American Journal of Energy Engineering
$2021 ; 9(1): 1-7$
http://www.sciencepublishinggroup.com/j/ajee
doi: 10.11648 /j.ajee.20210901.11
ISSN: $2329-1648$ (Print); ISSN: $2329-163 \mathrm{X}$ (Online)

\title{
A Review of Cooking Systems and Energy Efficiencies
}

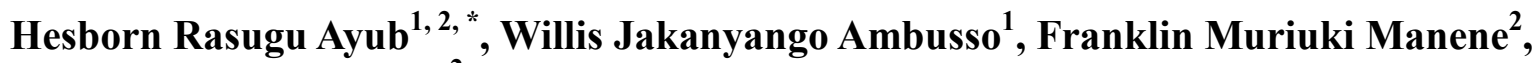 \\ Daudi Mongeri Nyaanga ${ }^{2}$ \\ ${ }^{1}$ Department of Energy Engineering, Kenyatta University, Nairobi, Kenya \\ ${ }^{2}$ Department of Industrial and Energy Engineering, Egerton University, Nakuru, Kenya \\ Email address: \\ hesborn.rasugu@egerton.ac.ke (H. R. Ayub), manenef@egerton.ac.ke(F. M. Manene), ambusso.willis@ku.ac.ke (W. J. Ambusso), \\ dmnyaanga@egerton.ac.ke (D. M. Nyaanga) \\ ${ }^{*}$ Corresponding author
}

\section{To cite this article:}

Hesborn Rasugu Ayub, Willis Jakanyango Ambusso, Franklin Muriuki Manene, Daudi Mongeri Nyaanga. A Review of Cooking Systems and Energy Efficiencies. American Journal of Energy Engineering. Vol. 9, No. 1, 2021, pp. 1-7. doi: 10.11648/j.ajee.20210901.11

Received: February 23, 2021; Accepted: March 16, 2021; Published: March 22, 2020

\begin{abstract}
Accessing affordable and reliable energy services for cooking is important in most developing countries. Improving access to affordable energy reduces effects on human health and environmental influences caused by burning of various biomasses. This review examines the energy resources available in the world and their use in cooking. It also looks at challenges and the ways these energy resources are used as well as possible solutions to such challenges. The major challenges facing the use of available fuels are low efficiencies, high cost, un-sustainability and indoor house pollution that affect many people. The paper has identified that the use of combustion-less cooking, the use of solar for cooking, hydrogen and electrical systems that improve cooking activities and therefore overcome indoor and environmental pollution. Research findings indicate that the pressure-cooking concept improves energy efficiencies in boiling operations. Other energy efficiency improvement techniques in cooking are insulation, containment of escaping steam while cooking and automating the cooking vessel with micro-controllers. The overall efficiencies for electrical induction heating, natural gas, traditional cooking stoves, fuel wood stoves and electrical resistive heating was found to be $90 \%, 45-60 \%, 10 \%, 23-40 \%$ and $75 \%$ respectively. Induction cooking is both faster and more efficient than gas cooking, while electrical energy systems as a whole were found to be the cleanest, offering ease of control and versatility. The combination of a micro-controller automated insulated pressure cooker and induction cooker can highly improve the cooking efficiency. This is done by cutting a power supply using a relay controlling an induction cooker and therefore preventing the exit of steam. It is therefore identified that zero emission release during cooking will reduce both indoor and environmental pollution significantly.
\end{abstract}

Keywords: Clean Cooking, Cooking Efficiency, Indoor Pollution, Induction Cooker, Pressure Cooker

\section{Introduction}

Thermal energy is essential for human life. Cooking is vital for feeding humankind, and boiled water is needed to fight infections [1]. Energy requirement is directly related to the development rate and the growth of population of any country in the world. Energy sources are classified into renewable and non-renewable sources. Biomass is among the kind of most abundant renewable energy resource in developing countries [2]. It is well known that improving access to cheap, clean and reliable modern forms of energy is important, particularly for developing countries, to reduce poverty and promote economic development [1]. Household cooking consumes more energy than any other activity in rural and urban areas of developing countries [3]. Energy required for cooking accounts for approximately $90 \%$ of all the domestic energy needs in many countries, and this is about $40 \%$ of Kenya's total energy consumption. Biomass sources, such as agricultural wastes and trees from forests, account for $80 \%$ of cooking energy in sub-Saharan Africa [4]. Other cooking energy sources are LPG, natural gas, electricity and kerosene. The choice of energy resource for cooking depends on its availability, affordability, ease of control and level of cleanliness. The scope of this paper is thus to evaluate and analyse the energy resources available and their use in cooking. Challenges and the ways energy resources are used as well as solutions to these challenges are also discussed. 


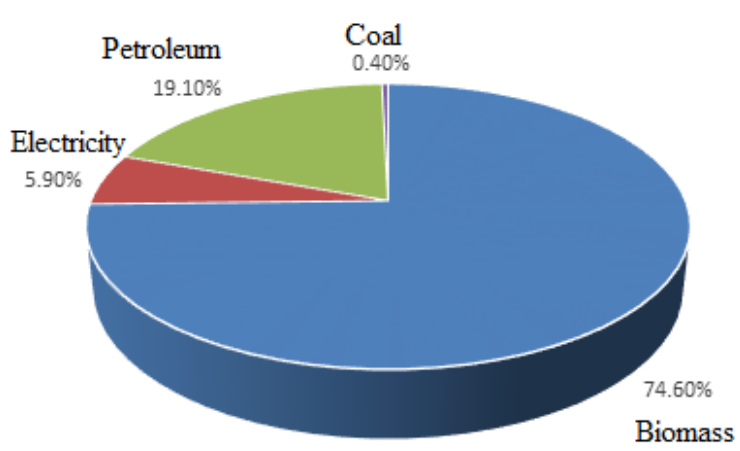

Figure 1. Energy Supply in Kenya [5].

Kenya, like many other African countries, relies heavily on biomass energy (firewood, charcoal and farm residues) mainly for domestic cooking, heating and for operating small - scale rural industries. Biomass fuels, mainly firewood and charcoal, have remained the main source of energy in Kenya. The energy balance of Kenya shows that biomass use accounts for over $74.6 \%$ of energy consumption. Petroleum and electricity accounts for about $19.1 \%$ and $5.9 \%$ respectively of Kenya's energy consumed while coal accounts for $0.4 \%$. This heavy dependence of biomass as the main energy source contributes to deforestation, while the importation of oil has forced the Nation to spend between $25 \%$ and $35 \%$ of her foreign earnings [5]. Although it is mainly used in domestic applications, biomass is the most abundant energy resource in Kenya as shown in Figure 1.

In Kenya, less than $10 \%$ of rural and urban households use alternative sources of energy other than biomass. About 70\% of the people in Kenya reside in rural areas, and it is only about $63.8 \%$ of them that have access to electricity, whereby $15 \%$ are connected to grid [6]. Due to improved standard of living, many people in the household level attempt to move up the energy ladder to start using safer, more accessible and cleaner sources of energy such as electricity and Liquefied Petroleum Gas (LPG). Kerosene has been used and is still used in rural areas for lighting purposes and its demand increases. Common cooking devices in the rural areas include the traditional three-stone fire, metal charcoal stoves, improved charcoal stoves and kerosene stoves. While fuels for cooking are relatively diverse (firewood, charcoal, kerosene, electricity, cow dung, crop residues, wood processing residues), wood-based biomass fuels stand out as the most important. However, in most rural areas of Kenya, the cooking process is done on three stones arranged triangularly to accommodate the pot, on traditional metal charcoal stoves and on the kerosene stoves as shown in Figure 2.
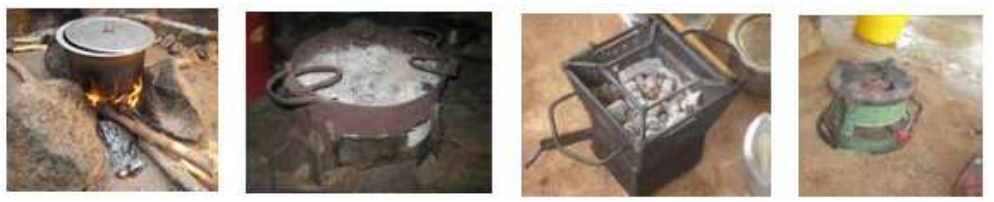

Figure 2. Three stone cooking, different traditional metal charcoal stoves and a kerosene stove [7, 8].

The use of kerosene is mainly limited to lighting, and quick cooking purposes for approximately one-third of low income houses. Kerosene is commonly used for cooking in urban areas as it facilitates quick cooking. As kerosene is widely used in Kenya for cooking, food sometimes takes the odor of its exhausts, and the smoke discourages many potential users. However, the most significant constraint against the wider use of kerosene is its cost, and the expenditure for special equipment such as kerosene stoves. At present, one litre of kerosene costs about 94 Kenyan shillings and therefore calls for alternative sources of energy (wood, crop residues and cow dung) [9]. The use of Liquid Petroleum Gas (LPG) by low income households is almost negligible. LPG's low uptake is due to the difficulty of accessing gas stations in rural surroundings and the high cost of buying LPG and its expensive accessories. The constant use of biomass in poorly ventilated households has led to indoor pollution and respiratory diseases. Access to safe, clean and reliable energy is a key driver to development for people in Kenya. This has led to newer and improved forms of renewable energy use, especially biomass gasification and biogas production.

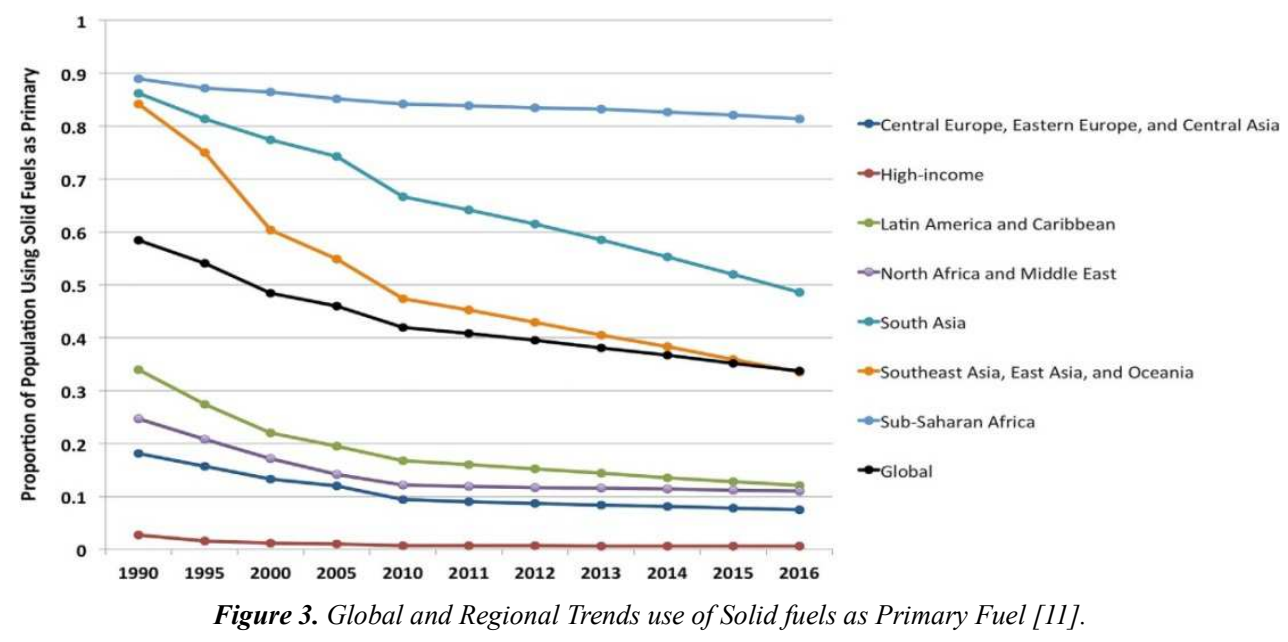


As shown in Figure 3, the global solid fuel use is declining with time which is likely caused by indoor pollution, improvement of economic position of people and the Technology advancement. Despite this, world energy demand grows by $8.1 \%$ annually as the world population grows. This emphasizes the need to make available energy resources more sustainable [10].

\section{Cooking Energy}

Figure 4 shows the various ways of defining household cooking energy types. Basing on the typical level of development, cooking energy can be categorized as traditional energy type which comprise of animal dung, agricultural residue and firewood, Intermediate energy types are such as wood pellets, charcoal, briquettes, lignite, coal and kerosene. Modern types of energy are solar, LPG, biogas, natural gas, electricity, gel fuel and plant fuels. On the other hand, primary and secondary energy base on how they are extracted. The energy types obtained from natural resources like firewood, agricultural waste, animal dung, coal, solar and natural gas are known as primary energy source. Secondary energy types are obtained after transformation of primary energy types and example here is when kerosene and LPG are extracted from petroleum crude oil, ethanol are produces from sugar cane, wood pellets and charcoal are obtained from fuel wood, from animal dung and agricultural wastes. Electricity is produced from combustion of fossil fuels and from renewables such as solar, hydro and wind. For the level of consumption, the cooking energy also are categorized into urban and income, where there are rural and urban as well as high and low-income households. Various cookstoves are used by households and are associated with specific energy types. Traditional three stoves, clay pot types and simple ceramic liners, charcoal, gasifier stoves which use solid fuels are more used in rural areas.

Biomass and fossil fuel are used in their raw forms for combustion-based cooking. The other most sources are converted into electricity first, for it to be used for combustion-less cooking. Renewable energy resources are used either directly to cook or indirectly to generate electricity. Solar parabolic cookers like the one shown in Figure 5 are the example of the direct application of solar energy. The sun is the major source of renewable energy since it powers wind, hydro power, biomass, tidal waves and Ocean Thermal Energy Technology (OTEC). Solar cookers include parabolic cookers, box cookers and Scheffler cookers [7].
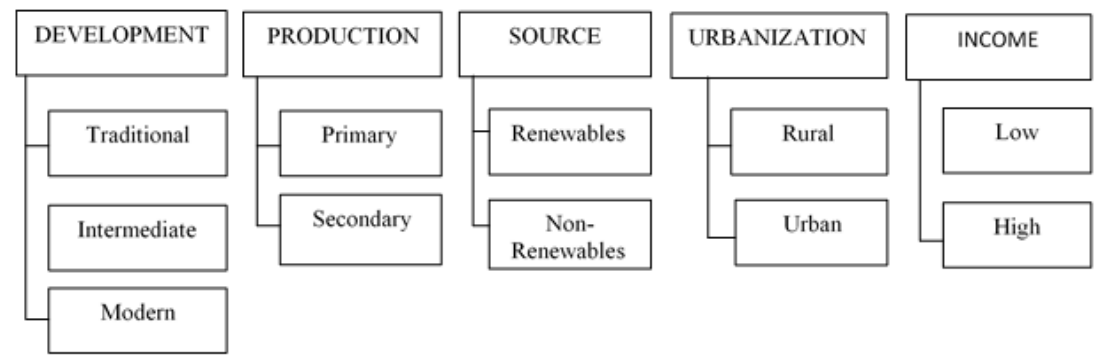

Figure 4. Categories of Household Cooking Energy Types [7, 12].

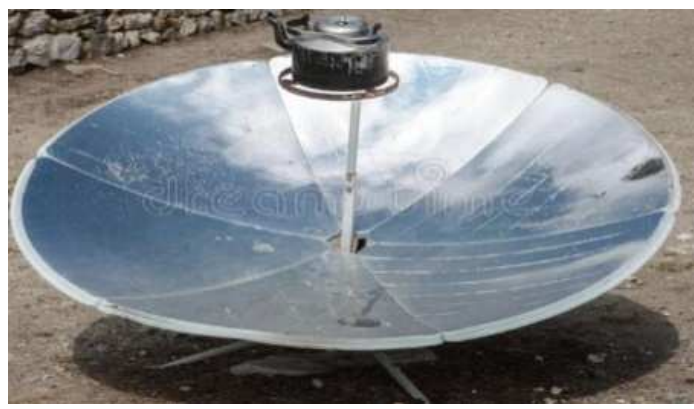

Figure 5. A Solar parabolic cooker [7, 13].

A small population in rural areas of developing countries uses solar appliances for cooking purposes due to economic difficulties. A solar cooker is an appliance which uses sunlight directly to heat, cook, bake or pasteurize food and drinks. It depends on the sun shine to work and therefore cannot be a stand-alone technology. Solar is a clean source of energy for domestic cooking [7] and institutional cooking [8]. Other researchers have proposed the use of solar induction stoves that are very efficient and option for clean cooking [13]. These new methods of using solar energy directly are more sustainable for cooking. Solar is eco-friendly, clean and cheaper.

\section{Cooking Energy and Cleanliness}

According to (IEA, 2017) about 2.8 billion people in the world and only $50 \%$ of the people in the developing countries have access to clean cooking. The remaining population use biomass and other fossil fuels for cooking. Most of countries especially Sub Sahara Africa, 90\% of the households uses wood, charcoal and waste for cooking. Preparing and collecting these fuels require many hours hence affecting women and children. These fuels, when burned, create noxious fumes which affect people as well as premature death.

Most fuels are hydrocarbons which burn to produce $\mathrm{CO}_{2}$, $\mathrm{CO}, \mathrm{H}_{2} \mathrm{O}, \mathrm{N}_{2}$ and traces of $\mathrm{NO}_{2}$ and $\mathrm{SO}_{2}$. Carbon dioxide gas is produced by combustion of fossil fuels and biomass which causes ozone layer depletion leading global warming and climate change. About 3 billion people in the world rely on 
solid fuels and kerosene for their cooking needs. Exposure to household air pollution from burning these fuels accounts for approximately 3 million premature deaths each year [13-15] and different illnesses such as heart disease, childhood pneumonia, chronic respiratory diseases, eye disease, cardiovascular disease, cancers, burns and cataracts [16-17]. World Health Organisation puts annual premature deaths due to respiratory complications at 7 million annually [18]. This data emphasizes the need to substitute solid fuels with cleaner options. There has thus been a decline in global use of solid fuel and kerosene stoves for daily household energy needs as depicted in Figure 1 above.

Generally, women do most of the cooking in homes and, therefore are disproportionately affected by household air pollution caused by the inefficient burning of solid biomass cooking fuels $[18,19]$. Despite several existing efficient and clean cooking energy systems, households generally do not prefer them [18-20]. The reason could be the high initial cost of purchase and reluctance to drop their traditional cooking methods. Charcoal and firewood will remain the main sources of cooking fuel for the next three decades. Corresponding energy policies are needed which set proper priorities and improve the sustainability of the biomass energy sector [21]. The use of efficient cooking stoves can potentially save fuel and reduce the health risks of smoke in the kitchen [22]. The introduction of new biomass technologies such as Improved Cooking Stoves (ICS), despite having a chimney for emptying smoke to outside and avoiding indoor pollution, have a low rate of adoption. The cooking stoves applied in the rural households have been made very simple and their disadvantage is that, they cannot remove biomass smoke during cooking because of their poor design. This cause low thermal efficiency as well as high levels of indoor air [23]. The access to clean cooking fuels and technologies is essential for achieving the Sustainable Development Goals (SDG), particularly in developing countries, to minimize impacts on human health and environment [24].

A shift to clean fuel like LPG and other modern gas stoves will bring significant health and environmental benefits, but only with proper and consistent use. Gas cooking is an important source of airborne fine particulate matter indoor because exposure to cooking-derived fine particulate matter will lead to adverse human health impacts on non-smokers, especially in poorly-ventilated residential homes [25]. Sharma and Balasubramanian recommend carbon-free combustion methods of cooking such as solar, electric and hydrogen cooking [26]. Solar cooking has reliability issues while hydrogen cooking is a new concept. Electric cooking is very clean and combustion free. The major challenges to electrical cooking are the high cost of electrical power and low electrification rates in some developing countries. Table 1 shows three categories of cleanliness for fuel as per their effect in indoor pollution. Biomass and fossil fuels undergo incomplete combustion, releasing particulate matter and emissions that are dangerous to life [27]. Hydrogen undergoes clean combustion to release water, while electricity is combustion-less and clean source of cooking energy.

Table 1. Cooking Energy in Cleanness Aspect [25, 27].

\begin{tabular}{lll}
\hline Level of Clean Cooking & Forms & Side Effects \\
\hline \multirow{2}{*}{ Unclean Cooking } & Fuel wood, Cow dung, Coal, Peat, & $\begin{array}{l}\text { Most undergo incomplete combustion thus producing fine black carbon, carbon } \\
\text { Kerosene, Pellets }\end{array}$ \\
monoxide, carbon dioxide and chlorofluorocarbons that cause respiratory problems. \\
Clean cooking & Smokeless biomass gasifier and LPG burners & $\begin{array}{l}\text { They undergo complete combustion but produce carbon dioxide and carbon aerosols } \\
\text { that cause respiratory problems. }\end{array}$ \\
Cleanest cooking & Solar, Electrical and Hydrogen cooking. & $\begin{array}{l}\text { Hydrogen undergoes combustion but produces water, no carbon compounds. Other } \\
\text { sources don't undergo combustion hence no gases emitted. }\end{array}$ \\
\hline
\end{tabular}

Efforts have been made to reduce indoor pollution by replacing kerosene lanterns with solar lighting kits. This is a good move but because lighting accounts for only $10 \%$ of indoor pollution, the problem of pollution from cooking has to be solved. WHO recommends cooking by combustion of hydrogen or, if carbon sources are used, the flue gases must be expelled from indoor air [27]. Figure 6 shows that people in South Africa use electricity for cooking in about $80 \%$ of urban homes and in $60 \%$ of rural areas [3]. This is due to high grid connectivity in South Africa and high level of electrification. This shows that electrical cooking is a reality and can be achieved. Other countries in east, west, central and southern African states use biomass for cooking in about $80 \%$ of rural and $60 \%$ of urban areas [28]. This is because these countries have the lowest electrification rate, and the number of rural population without electricity is high. The major challenges in most of African countries are the low electrification rates, poor grid connection and low power generation.

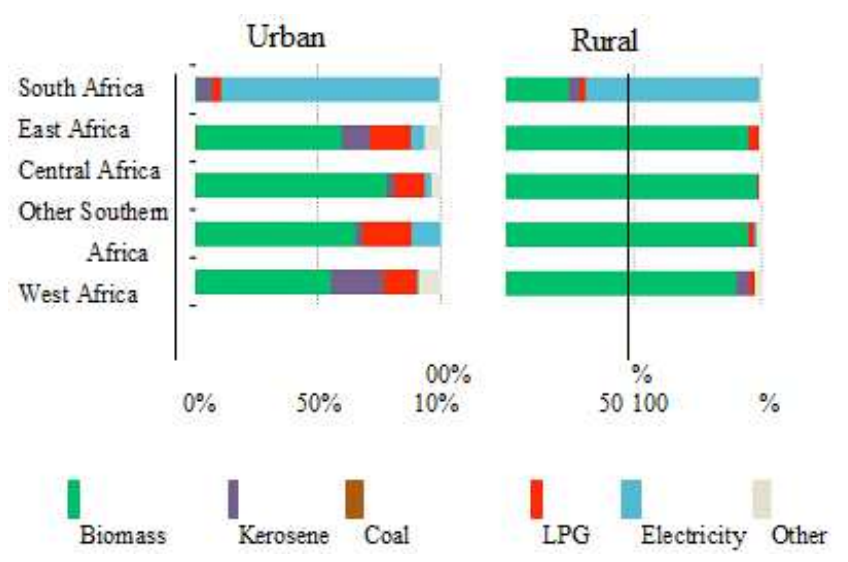

Figure 6. Cooking Fuels in Africa [3].

The annual electrical energy consumption for cooking per household in most developing countries is $3232 \mathrm{kWh}$ which is about $9 \mathrm{kWh}$ per day [3]. With an efficiency improvement on 
the vessel side this daily energy use can be supplied by using solar PV [27] and this was supported by Watkins who reported that small food quantities cook well for a family by incorporating insulation to the cookers [29]. The authors recommend that the cooker can be fitted with a gas or battery back-up in non-grid areas to overcome major electrical challenges of cost and availability. Sibiya also proved that solar PV can support an induction cooker which can have a battery back-up for night cooking [30].

\section{Cooking System Energy Efficiencies}

The efficiency of a cooking system is the ratio of energy output at the cooking vessel to the energy from source at the input side. When the efficiency is low, more energy input is required for the same amount of food to be cooked, compared to a more efficient cooking system. The lower the efficiency the more energy needed. This situation leads to over-exploitation of the available energy resources, and so efficiency improvements are needed for sustainable energy systems. Studies have shown that the efficiencies of cooking systems such as traditional 3-stone fires and improved cook stoves is about $10 \%$ and $23-40$ respectively [31]. Efficiency for gas cooking is $45-60 \%$ and of electrical resistive cooking is about $75 \%$. Efficiency of inductive cooking systems was about $90 \%$ [32] and the consumption efficiencies when boiling water were reported as $25 \%, 46 \%$, $73 \%, 79 \%, 66 \%$ and $90 \%$ for fuel wood, kerosene, gas, electric immersion coil, electric heating coil and electric hot plate, respectively [33]. The electric hot plate with its resistive element is $90 \%$ efficient provided that the vessel is larger than the hot plate [32-33]. When they are equal in size, the efficiency reaches about $75 \%$. The induction cooker has a constant efficiency of $90 \%$ as it incorporates sensors to determine the size of the cooking vessel and it adjusts the area that it magnetises. Induction cooking is thus widely used for its high efficiency and safety [34]. Although induction cookers heat cook faster than gas [32-35], the major challenges for their adoption in domestic use are initial high cost and the need to replace cooking vessels to ferromagnetic compliant ones.

\section{Methods Applied to Improve Cooking Efficiency}

Energy can be lost from the cooking systems through various ways. One of these ways is the heat loss to the environment by both the cooking vessel and heat source, through basic heat transfer mechanism of radiation, conversion and conduction resulting to poor heat transmission. Another way is the escape of heated steam in boiling, which will lower the internal energy of the water or food being cooked. Any improvement in cooking efficiency reduces the energy input, thus decreasing demand on energy resources in the world, hence reducing the carbon footprint [36]. The main challenge associated with the present ordinary pressure cookers is the steam release (whistling) hence heat loss to the environment. A well-insulated pressure cooker, made with the ability of not releasing steam during cooking will improve cooking efficiency and as a result save energy.

\subsection{Insulation}

Insulating materials reduce heat transfer losses from the vessel's or oven's side to the environment. Examples of insulating materials used are air, vacuum in a thermos flask, and rock wool. The fireless cooker is a good example of an almost adiabatic state with almost zero heat loss to the environment. Food can be brought to boiling point and then put in very well-insulated fireless cooker, where it cooks without any extra energy [29]. Solar cooking that utilizes insulation achieves effective energy storage [37]. Employing this insulation technology in an ordinary induction pressure cooker vessel can result in significant energy savings.

\subsection{Pressure Cooking}

Pressure cooking entails cooking by food in a closed vessel at high temperature with steam at $120^{\circ} \mathrm{C}$ and therefore a pressure of 1.5 bars will forces steam into the cooking food, hence cooking them faster [38]. There is energy loss from the food when the pressure-valve opens for safety, which escapes with energy [39]. From the review it is concluded that a new approach is needed for the pressure cooker where the cooking is done in a well-insulated pressure cooker powered by an induction cooker without release of steam, with the safety valve in its closed position.

\subsection{Automating}

The pressure cooker can be automated with the use of a micro-controller which switches an electric cooker off just before steam escapes through the safety valve. Pressure sensors control a relay that switches the heating device on and off, which conserves energy by preventing steam escape. Svosve and Gudukeya have demonstrated an automated stove which prevents the burning of food and powers off when it senses that there is no food to cook [40]. Automation controls energy input resulting in energy economy [41] in smart solar cooking systems [42].

\section{Conclusion}

This study has successfully explored cooking systems for their cleanliness, efficiencies and sustainability, which was the main aim of the review paper. Electrical cooking was found to be clean, with induction heating giving the fastest and most efficient cooker. Electrical energy for cooking is clean with ease of control and can support other domestic uses. It is necessary to make it more available, affordable, and sourced from renewable energy. The pressure cooker offers energy savings by avoiding steam release, by switching power off and on, using a micro-controller. In this study it proposes research on the possibility of using a system that combines induction cooking technology with an insulated pressure cooker which 
is automated with a micro-controller for steam containment. This will prevent most energy losses to the environment, cut indoor pollution and reduce carbon dioxide emissions from combustion. The use of less energy in cooking from electrical renewable resources will help reduce demand for unsustainable energy resources, such as forests residues. This will have a double effect in mitigating climate change, which is one of the Sustainable Development Goals (SDG).

\section{Acknowledgements}

The authors would like to acknowledge the assistance and financial support provided by Egerton University during the study of this work. They also recognize the support given by the management and staff of the Energy engineering Department at Kenyatta University, so that this this study could be successfully completed.

\section{References}

[1] Nogueira, I., Legrand, M., \& Lecuona-neumann, A. 2018. Photovoltaic Cooking. Advances in Renewable Energies and Power Technologies, 403-427.

[2] Komala, H. P., Devi Prasad, A G. (2016). Biomass: A key source of energy in Rural households of Chamarajanagar District. Advanced in applied Science Research, 7 (1), 85-85.

[3] International Energy Agency-IEA (2017). World Energy Outlook-2017, OECD/IEA, Paris.

[4] Van Der Plas R. Haiti (2007). Strategy to alleviate the pressure of fuel demand on national wood fuel resources. Republic of Haiti Ministry of Environment, Bureau of Mines and Energy, Energy Sector Management Assistance Program technical paper no. 112/07.

[5] Kiplagat, J., Wang, R., Li, T. (2011). Renewable energy in Kenya: Resource potential and status of exploitation. Renewable and sustainable energy reviews, 15, 2960 - 2973.

[6] Mumbo, A., Bess, C., Mutua, F. (2020). Renewable Energy: The paradigm shift- Energy, Development and climate change, Kenya South Africa context. Journal of Engineering in Agriculture and the environment, volume, 6, no. 2.

[7] Prabhu, A. V., Jeba, P., Babu, R., Kumar, P. S. (2018). A Review of solar based induction cooker using different topologies. International Journal of Scientific Research and Review, 7 (10), 26-30.

[8] Indora, S., \& Kandpal, T. C. (2018). Institutional cooking with solar energy: A review. Renewable and Sustainable Energy Reviews, 84, 131-154.

[9] Energy Regulatory Commission of Kenya (EPRA) (2021). www.epra.go.ke

[10] Lambe, F. (2015). Bringing clean, safe, affordable cooking energy to households across Africa: an agenda for action, Stockholm Environment Institute, Stockholm.

[11] Baumgartner, J. (2019). Household Energy Solutions in Low and Middle-Income Countries.
[12] Sunil M, Timilsina, G. R. (2014). Household Cooking Fuel Choice and Adoption of Improved Cookstoves in Developing Countries a Review. A World Bank Policy review paper.

[13] Banerjee, M., Prasad, R., Rehman, I. H., Gill, B. (2016). Induction stoves as an option for clean cooking in rural India. Energy Policy, 88, 159-167.

[14] Kumar, P., Igdalsky, L. (2019). Sustained uptake of clean cooking practices in poor communities: Role of social networks. Energy Research \& Social Science, 48, 189-193.

[15] Mazorra, J., Sánchez-jacob, E., De, C., Fernández, L., Lumbreras, J. (2020). A comprehensive analysis of cooking solutions co-benefits at household level: Healthy lives and well-being, gender and climate change. Science of the Total Environment, 707, 135968.

[16] Quinn, A. K., Bruce, N., Puzzolo, E., Dickinson, K., Sturke, R., Jack, D. W., Rosenthal, J. P. (2018). Energy for Sustainable Development: An analysis of efforts to scale up clean household energy for cooking around the world. Energy for Sustainable Development, 46, 1-10.

[17] Jewitt, S., Atagher, P., Clifford, M. (2020). “ We cannot stop cooking ": Stove stacking, seasonality and the risky practices of household cookstove transitions in Nigeria. Energy Research \& Social Science, 61, 1-10.

[18] World Health Organization-WHO. (2014). Indoor Air Quality Guidelines: Household Fuel Combustion. Geneva: World Health Organization.

[19] Bloomfield, D. E., Malla, M. B. (2014). Gender and Livelihoods Impacts of Clean Cook stoves in South Asia. Global Alliance for Clean Cook stoves. Retrieved May 16, 2018, from

https://cleancookstoves.org/binary-data/RESOURCE/file/000/ 000/363-1.

[20] Ihalainen, M., Schure, J., Sola, P. (2020). Where are the women? A review and conceptual framework for addressing gender equity in charcoal value chains in Sub-Saharan Africa. Energy for Sustainable Development, 55, 1-12.

[21] Das, K., Pradhan, G., Nonhebel, S. (2019). Human energy and time spent by women using cooking energy systems: A case study of Nepal. Energy, 182, 493-501.

[22] Batchelor, S., Brown, E., Leary, J., Scott, N., \& Leach, M. (2018). Solar electric cooking in Africa: Where will the transition happen first? Energy Research \& Social Science, 40, 257-272.

[23] Njenga, M., Iiyama, M., Jamndass, R., Helander, H., Larsson, A., Leeuw, J. De, Sundberg, C. (2016). Gasifier as a cleaner cooking system in rural Kenya. Journal of Cleaner Production (put numbers).

[24] Geremew, K., Gedefaw, M., Dagnew, Z., Jara, D. (2014). Current Level and Correlates of traditional Cooking Energy Sources Utilization in Urban Settings in the Context of Climate Change and Health, Northwest Ethiopia: A Case of Debre Markos Town. BioMed Research International, 1-10.

[25] Mikhail, J., Gallego-schmid, A., Stamford, L., Azapagic, A. (2020). Environment Environmental sustainability of cooking fuels in remote communities: Life cycle and local impacts. Science of the Total Environment, 713, 136445. 
[26] Sharma, R., Balasubramanian, R. (2020). Evaluation of the effectiveness of a portable air cleaner in mitigating indoor human exposure to cooking- derived airborne particles. Environmental Research, 109192.

[27] WHO. (2018). Burden of disease from household air pollution for 2016.

https://www.who.int/airpollution/data/HAP_BoD_results. [Accessed 21/03/2019]

[28] Clancy, J. (2004). Enabling urban poor livelihoods policy making: understanding the role of energy services. UK Department for International Development (DFID) Inception Report, 2004.

[29] Watkins, T., Arroyo, P., Perry, R., Wang, R., Arriaga, O., Fleming, M., Stone, I. (2017). Insulated Solar Electric Cooking - Tomorrow's healthy affordable stoves? Development Engineering, 2, 47-52.

[30] Sibiya, Bandile I., Venugopal, C. (2017). Solar Powered Induction Cooking System. Energy Procedia, 117, 145-156.

[31] Zhang, J., K. R. Smith, Y. Ma, S. Ye, F. Jiang, W. Qi, P. Liu, M. A. K. Khalil, R. A. Rasmussen, and S. A. Thorneloe. (2000). Greenhouse gases and other airborne pollutants from household stoves in China: a database for emission factors. Atmospheric Environment, 34 (26), 4537-4549.

[32] Sadhu, P. K., Nitai, P., Atanu, B., Sinha, D. (2010). Review of induction cooking- A health hazards free tool to improve energy efficiency as compared to microwave oven.

[33] Anozie, A. N., Bakare, A. R., Sonibare, J. A., Oyebisi, T. O. (2007). Evaluation of cooking energy cost, efficiency, impact on air pollution and policy in Nigeria. Energy, 32, 1283-1290.
[34] Cao, L., Yin, T., Jin, M., \& He, Z. (2019). Flexible circulated-cooling liquid metal coil for induction heating. Applied Thermal Engineering, 162, 114260.

[35] Martínez-gomez, J., Ibarra, D., Villacis, S., Cuji, P., Cruz, P. R. (2016). Analysis of LPG, electric and induction cookers during cooking typical Ecuadorian dishes into the national efficient cooking program. Food Policy, 59, 88-102.

[36] Cimini, A., Moresi, M. (2017). Energy efficiency and carbon footprint of home pasta cooking appliances. Journal of Food Engineering, (which volume)

[37] Kumaresan, G., Vigneswaran, V. S., Esakkimuthu, S., Velraj, R. (2016). Performance assessment of a solar domestic cooking unit integrated with thermal energy storage system. Journal of energy storage, 6, 70-79.

[38] Kar, A., Singh, D., Zerriffi, H. (2018). Has India's Ujjwala Program enabled millions to shift to Liquefied Petroleum Gas as a primary cooking fuel? Available online:

[39] Date, D. D, Tated R G., (2018). Pressure cooker lid - Literature review. International Journal of Advance Research, Ideas and Innovations in Technology (IJARIIT). 4 (3), 2388-96.

[40] Svosve, C., Gudukeya, L. (2020). A Smart Smart Electric Electric Cooking Cooking Stove Stove. Procedia Manufacturing, 43 (2019), 135-142.

[41] Das, T., Subramanian, R., Chakkaravarthi, A., Singh, V., Ali, S. Z., Bordoloi, P. K. (2006). Energy conservation in domestic rice cooking. Journal of Food Engineering, 75, 156-166.

[42] Sibiya, Bandile I. (2017). Smart Induction Cooking System Using Solar Energy. University of KwaZulu-Natal. Unpublished Master's Thesis. 